\title{
A Phase I proof-of-concept and safety trial of sildenafil to treat cerebral vasospasm following subarachnoid hemorrhage
}

\author{
Chad W. Washington, MS, MD, MPHS, ${ }^{1,3}$ Colin P. Derdeyn, MD,,-3 Rajat Dhar, MD, ${ }^{2}$ \\ Eric J. Arias, MD, ${ }^{1}$ Michael R. Chicoine, MD,, DeWitte T. Cross, MD, ${ }^{1,3}$ Ralph G. Dacey Jr., MD, ${ }^{1}$ \\ Byung Hee Han, PhD, ${ }^{1}$ Christopher J. Moran, MD, ${ }^{1,3}$ Keith M. Rich, MD, ${ }^{1,3}$ Ananth K. Vellimana, MD, \\ and Gregory J. Zipfel, MD',2
} Departments of ${ }^{1}$ Neurological Surgery, ${ }^{2}$ Neurology, and ${ }^{3}$ Radiology, Washington University School of Medicine, Saint Louis,
Missouri

OBJECTIVE Studies show that phosphodiesterase-V (PDE-V) inhibition reduces cerebral vasospasm (CVS) and improves outcomes after experimental subarachnoid hemorrhage (SAH). This study was performed to investigate the safety and effect of sildenafil (an FDA-approved PDE-V inhibitor) on angiographic CVS in SAH patients.

METHODS A 2-phase, prospective, nonrandomized, human trial was implemented. Subarachnoid hemorrhage patients underwent angiography on Day 7 to assess for CVS. Those with CVS were given $10 \mathrm{mg}$ of intravenous sildenafil in the first phase of the study and $30 \mathrm{mg}$ in the second phase. In both, angiography was repeated 30 minutes after infusion. Safety was assessed by monitoring neurological examination findings and vital signs and for the development of adverse reactions. For angiographic assessment, in a blinded fashion, pre- and post-sildenafil images were graded as "improvement" or "no improvement" in CVS. Unblinded measurements were made between pre- and post-sildenafil angiograms.

RESULTS Twelve patients received sildenafil; 5 patients received $10 \mathrm{mg}$ and 7 received $30 \mathrm{mg}$. There were no adverse reactions. There was no adverse effect on heart rate or intracranial pressure. Sildenafil resulted in a transient decline in mean arterial pressure, an average of $17 \%$ with a return to baseline in an average of 18 minutes. Eight patients (67\%) were found to have a positive angiographic response to sildenafil, $3(60 \%)$ in the low-dose group and $5(71 \%)$ in the highdose group. The largest degree of vessel dilation was an average of $0.8 \mathrm{~mm}$ (range 0-2.1 mm). This corresponded to an average percentage increase in vessel diameter of $62 \%$ (range $0 \%-200 \%$ ).

CONCLUSIONS The results from this Phase I safety and proof-of-concept trial assessing the use of intravenous sildenafil in patients with CVS show that sildenafil is safe and well tolerated in the setting of SAH. Furthermore, the angiographic data suggest that sildenafil has a positive impact on human CVS.

http://thejns.org/doi/abs/10.3171/2015.2.JNS142752

KEY WORDS subarachnoid hemorrhage; aneurysm; delayed cerebral ischemia; cerebral vasospasm; vascular disorders

A NEURYSMAL subarachnoid hemorrhage (SAH) is a significant health care problem with high morbidity and mortality; up to $70 \%$ of patients will die or be permanently disabled. ${ }^{33}$ Prognosis is dependent on a number of factors such as age, presenting neurological status, and development of delayed cerebral ischemia (DCI).,6,74 Occurring in $30 \%-40 \%$ of patients, DCI is the most common and potentially treatable contributor to outcome. ${ }^{6,57,78}$
Though the mechanisms underlying DCI are multifactorial, the processes considered most responsible are delayed cerebrovascular vasospasm (CVS), cerebrovascular autoregulatory dysfunction, and cortical spreading ischemia. ${ }^{6,47}$ Unfortunately, to date few therapies have proven effective for the prevention and treatment of DCI. ${ }^{4,82}$

A significant predictor of developing DCI is angiographic CVS of intracranial vessels. ${ }^{6,7,47}$ Approximately

ABBREVIATIONS $\mathrm{CGMP}$ = cyclic guanosine monophosphate; $\mathrm{CVS}=$ cerebrovascular vasospasm; $\mathrm{DCl}=$ delayed cerebral ischemia; $\mathrm{DSA}=$ digital subtraction angiography; $\mathrm{DSMB}=$ Data Safety Monitoring Board; eNOS = endothelial nitric oxide synthase; ICA = internal carotid artery; ICP = intracranial pressure; MAP = mean arterial pressure; $\mathrm{MCA}=$ middle cerebral artery; NNICU = Neurology/Neurosurgery ICU; NO = nitric oxide; PDE-V = phosphodiesterase-V; SAH = subarachnoid hemorrhage.

SUBMITTED December 3, 2014. ACCEPTED February 23, 2015.

INCLUDE WHEN CITING Published online August 28, 2015; DOI: 10.3171/2015.2.JNS142752. 
$60 \%-70 \%$ of patients will have CVS on digital subtraction angiography (DSA), ${ }^{4,6,7,11}$ In those patients, $50 \%$ will develop DCI. ${ }^{7,8,17,61}$ With this strong correlation, it is recommended that CVS be used as an initial outcome measure when assessing potential treatments for DCI. ${ }^{13,78}$ However, as research continues to elucidate the multifactorial nature of DCI, future interventions will need to attack not only CVS, but other contributors to DCI as well.

We hypothesize that one such therapeutic target is phosphodiesterase-V (PDE-V) inhibition. PDE-V is the regulatory enzyme of the endothelial nitric oxide synthase $\rightarrow$ nitric oxide $\rightarrow$ cyclic guanosine monophosphate (eNOS-NO-cGMP) pathway. 19,27 Decreased functionality of this pathway following SAH has been linked to the pathophysiology of DCI including CVS. ${ }^{58,69,71,77,85}$ Studies investigating the eNOS-NO-cGMP pathway have shown that inhibition of PDE-V has substantial beneficial effects. In animal SAH studies, PDE-V inhibition (mainly via administration of sildenafil, an FDA-approved selective PDE-V inhibitor) acutely reverses SAH-induced CVS, $, 28,31,32,34,42$ reduces neuronal cell death, ${ }^{32}$ restores impaired autoregulatory mechanisms ${ }^{73}$ and improves neurological outcomes. ${ }^{32}$ In SAH patients, sildenafil has been shown to improve transcranial Doppler flow velocities. ${ }^{56}$ Beyond this, there are data suggesting that sildenafil beneficially affects additional contributors of brain injury after SAH. In studies of SAH in animals, sildenafil has shown to reduce plasma levels of endothelin- $1,9,25,26,44,47,55,60,64,65$ limit platelet induced microthrombosis, ${ }^{30,45,62,68,83}$ and promote cerebral angiogenesis in hypoxic areas. . $^{14,66,87-89}$

Sildenafil has been extensively studied and proven safe in both healthy and cardiovascularly ill patients. ${ }^{1,5,18,24,35,41,67,80,81,90,91}$ However, to date there have been no studies in humans providing rigorous data on the safety of sildenafil in the setting of SAH. The primary objective of this study is to assess the safety of intravenous sildenafil in patients with SAH-induced CVS. Second, as a proof-of-concept, we looked to determine the ability of sildenafil to reverse CVS.

\section{Methods}

\section{Study Design and Patient Population}

A Phase I prospective, nonrandomized human trial with intravenous sildenafil using a dose escalation scheme (10 $\mathrm{mg}$ or $30 \mathrm{mg}$ ) was implemented (Fig. 1). Figure 2 shows the timeline for patient enrollment and study completion. The protocol was reviewed and approved by the study institution's human research protection office. The US Food and Drug Administration granted an exemption from investigational new drug regulations. The trial was monitored by an independent Data Safety Monitoring Board (DSMB), led by a senior neurosurgeon with expertise in SAH management and clinical trials.

Patients admitted within 72 hours of an aneurysmal SAH were recruited from September 2011 through May 2013. Screening criteria included 1) age $\geq 21$ years, 2) surgical or endovascular repair of the ruptured aneurysm, 3) modified Fisher Grade I to IV hemorrhage ${ }^{23}$ on initial CT imaging, and 4) CVS on DSA. Exclusion criteria were 1)

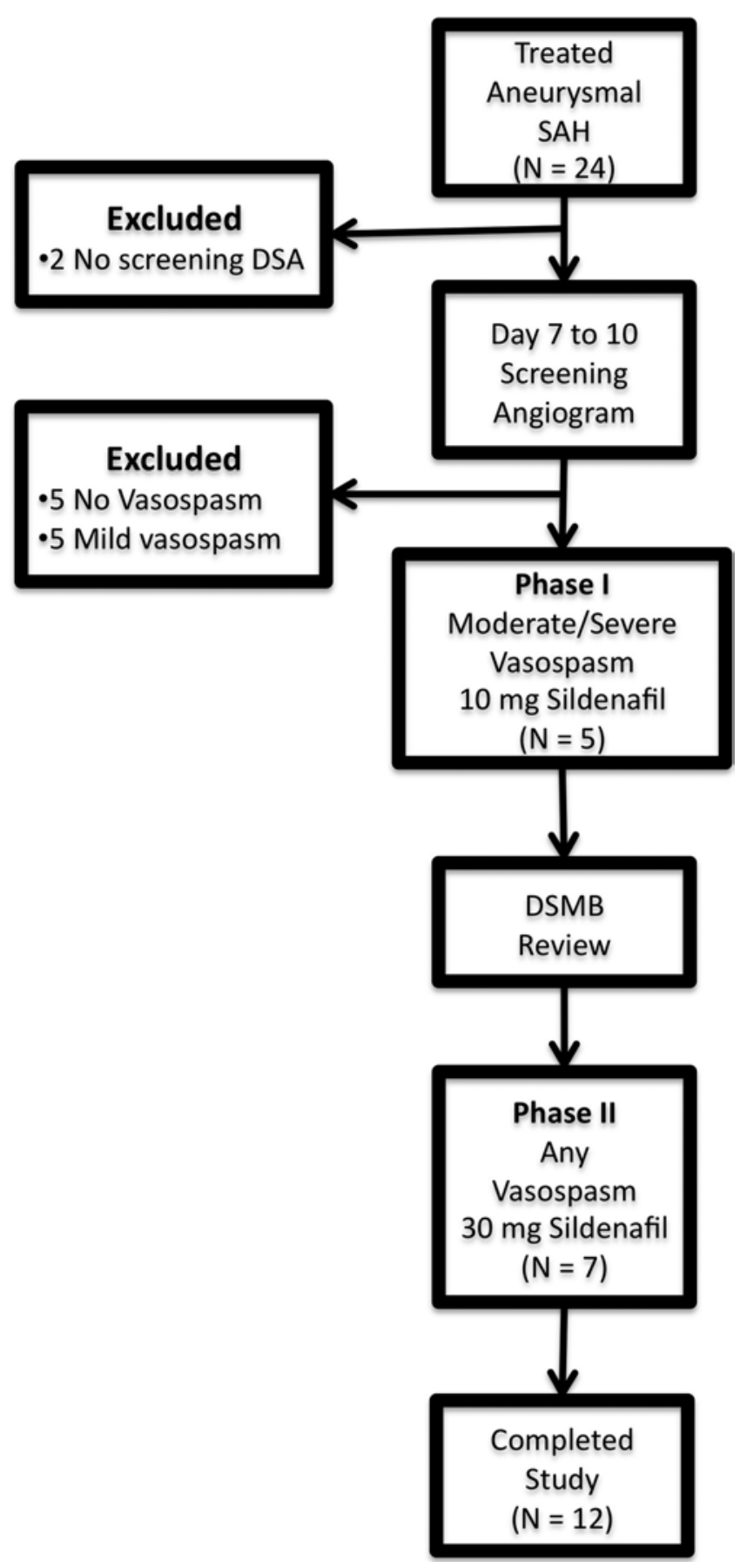

FIG. 1. Flowchart showing the study protocol with recruitment data. Twenty-four patients were enrolled, with 12 patients completing the study.

pregnancy, 2) SAH secondary to traumatic or mycotic aneurysm, 3) preictal sildenafil therapy, 4) contraindications to sildenafil therapy: use of nitrates and patients with left ventricular outflow obstruction, and 5) insufficient CVS on screening DSA.

\section{Study Interventions}

Per our established clinical protocol for SAH man- 


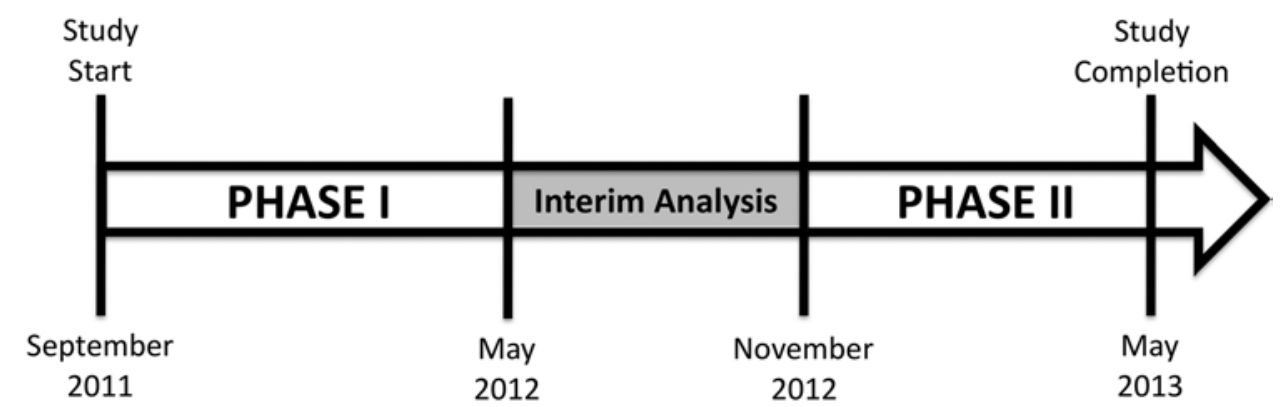

FIG. 2. Timeline for patient enrollment and study completion.

agement, patients were initially evaluated using DSA to determine the etiology of the SAH. Cerebral aneurysms were treated either surgically or endovascularly within 24 hours of admission. Following treatment, patients were monitored in the Neurology/Neurosurgery ICU (NNICU) throughout the vasospasm window.

All patients were given enteral nimodipine $(60 \mathrm{mg}$ every 4 hours) for 21 days, and fluid status was closely monitored. If a patient developed neurological worsening concerning for DCI, hypertensive treatment was initiated and evaluation with DSA and possible endovascular intervention (i.e., intraarterial verapamil and/or balloon angioplasty) was promptly arranged. In the absence of new symptoms, each patient underwent screening DSA to assess for CVS during the peak vasospasm period (Days $7-10)$.

\section{Sildenafil Dosing}

Based on dosages used in previous clinical trials evaluating sildenafil for the treatment of pulmonary hypertension, ${ }^{24}$ the study was carried out using a dose escalation scheme. Twelve patients were enrolled sequentially into 2 groups. During the first phase, patients with moderate to severe CVS (determined at the time of the screening DSA) received $10 \mathrm{mg}$ (low-dose) of intravenous sildenafil (bioequivalent to a 20-mg oral dose). After the planned midpoint safety review by the DSMB, the study proceeded to the high-dose phase. At this stage, patients with any degree of CVS (mild, moderate, or severe) found on their follow-up DSA study (determined at the time of the screening DSA) received $30 \mathrm{mg}$ (high dose) of intravenous sildenafil (bioequivalent to a $60 \mathrm{mg}$ oral dose).

Sildenafil was infused over 30 minutes, after which all patients were monitored for a further 30-minute interval. After this period a repeat DSA was obtained to assess for improvement of vasospasm. If CVS persisted, the patient could receive endovascular interventions as current standard of care (i.e., intraarterial verapamil or angioplasty).

\section{Safety and Tolerability Assessment}

The safety measures to be assessed were development of hypotension, elevated intracranial pressure (ICP, measured via external ventricular drain, when available), cardiac arrhythmias, or any decline in pulmonary or neurological status. Hypotension was defined as a decrease $>10 \%$ from the baseline mean arterial pressure (MAP). The duration of hypotension was also recorded as time to return to within $10 \%$ of baseline MAP. An adverse event related to hypotension was defined as either a decline in MAP $<70 \mathrm{~mm} \mathrm{Hg}$ or a decline in MAP that resulted in worsened neurological examination findings. As a comparison with sildenafil's effect on MAP, we analyzed the impact of nimodipine by measuring patients' prenimodipine and 1-hour postnimodipine MAP. Elevated ICP was considered as pressure $>25 \mathrm{~mm} \mathrm{Hg}$ for longer than $5 \mathrm{~min}$ utes. Further adverse events (those previously associated with sildenafil), for which patients were monitored, included priapism, visible flushing, and visual disturbances. After the procedure, monitoring of the patients continued in the NNICU with continuous vital sign monitoring and hourly neurological checks. Complete neurological and physical examinations were completed immediately prior to DSA, 1 hour post-sildenafil, and 12 hours post-sildenafil by a study physician.

\section{Radiological CVS Assessment}

At the time of the screening DSA, images were evaluated by one of the 3 neuorinterventional radiology investigators (D.T.C., C.P.D., and C.J.M.), and vasospasm was quantified as follows: comparing the screening angiogram to the admission angiogram, CVS in the internal carotid, basilar, middle, anterior, and posterior cerebral arteries was defined based on percent reduction in caliber size as none, mild $(<50 \%$ narrowing), moderate $(50 \%-70 \%$ narrowing), and severe (> 70\% narrowing). ${ }^{54}$ For each patient the most significant percent reduction of caliber size in any single vessel was the recorded degree of CVS. Vessel measurements were made using software on the Axiom Artis unit (Siemens Healthcare).

Postprocedural analyses of DSA images to determine whether patients showed any evidence of response to sildenafil were completed by 2 authors (C.P.D. and C.W.W.). In a blinded fashion, reviewers labeled images as "admission," "pre-sildenafil," and "post-sildenafil." After labeling, images were compared and subjectively graded as "improvement" or "no improvement" in vasospasm.

A quantitative analysis of images was carried out to determine the magnitude of response. Unblinded measurements of vessel diameter were made on the admission, pre-sildenafil, and post-sildenafil DSA images. Measurements were made in millimeters at the highest degree of stenosis in each of the supraclinoidal segment of the internal carotid artery (ICA), $A_{1}$ and $A_{2}$ segments of the anterior cerebral artery, the $\mathrm{M}_{1}$ and $\mathrm{M}_{2}$ segments of the 
middle cerebral artery (MCA), the basilar artery, and posterior cerebral arteries. The petrous ICA or the cervical vertebral artery was used as a reference to correct for magnification. Change in stenosis was calculated in millimeters and by percent change from pre-sildenafil baseline measurements. For each patient the largest improvement in any single vessel was the recorded response.

\section{Statistical Analysis}

All statistical analyses were completed using SAS (version 9.3, SAS Institute Inc.). Comparisons of continuous patient data pre- and post-sildenafil used a paired t-test, whereas comparisons made across low-dose and highdose groups used a 2-sample t-test. Categorical variables across groups were compared using Fisher's exact t-test. For statistical tests, significance was defined as $\mathrm{p}<0.05$.

\section{Results}

\section{Patient Population}

Twenty-four patients provided consent for the study, and 12 were excluded for not undergoing repeat DSA (n $=2$ ) or having insufficient degree of angiographic vasospasm $(n=10)$. Twelve patients received sildenafil; $5(42 \%)$ were in the low-dose $(10 \mathrm{mg})$ group and $7(58 \%)$ were in the high-dose $(30 \mathrm{mg})$ group. Demographic data are provided in Table 1 . Most patients $(66 \%)$ were in Hunt and Hess Grade III or IV, and $92 \%$ of patients had modified Fisher Grade III or IV SAH.

\section{Safety and Tolerability}

There were no adverse pulmonary or neurological events. All patients accessible for subjective assessment tolerated the doses without complaint of worsening headache, flushing, or visual changes. All neurological examination findings remained stable. One patient showed improvement after infusion, with resolution of a pronator drift.

Data regarding blood pressure, ICP, and heart rate can be found in Table 2. (With the following data, averages are given with standard deviations in parentheses.) Ten of 12 patients (83\%) developed hypotension following sildenafil, with greatest decline in MAP an average of $17 \%$ (SD 9\%) below baseline. The change was transient in all cases, with return to baseline occurring by an average of 18 (SD 15) minutes. The magnitude of this decline was not significantly different from that seen in patients following nimodipine, which was an average of $11 \%$ (SD 6). There were no differences in the degree of hypotension between low- and high-dose groups, and return to baseline MAP occurred by 16 and 20 minutes, respectively (differences all nonsignificant). No patient had a hypotension-related adverse event.

There was no significant change between pre- and post-sildenafil ICP or heart rate. No patient had elevated ICP within the 24-hour period following sildenafil therapy.

\section{Angiographic CVS}

Individual angiographic data for patients are shown in Table 3. Of the 12 patients completing the study, 1 (8\%)
TABLE 1. Patient demographics and admitting characteristics*

\begin{tabular}{|c|c|}
\hline Variable & Value \\
\hline Mean age in yrs (range) & $55(38-83)$ \\
\hline \multicolumn{2}{|l|}{ Sex } \\
\hline Male & $6(50)$ \\
\hline Female & $6(50)$ \\
\hline \multicolumn{2}{|l|}{ Hunt \& Hess grade } \\
\hline 1 & $0(0)$ \\
\hline II & $3(25)$ \\
\hline III & $4(33)$ \\
\hline IV & $4(33)$ \\
\hline V & $1(8)$ \\
\hline \multicolumn{2}{|c|}{ Hydrocephalus on admission } \\
\hline Yes & $10(83)$ \\
\hline No & $2(17)$ \\
\hline \multicolumn{2}{|l|}{ Modified Fisher grade } \\
\hline I & $1(8)$ \\
\hline II & $0(0)$ \\
\hline III & $6(50)$ \\
\hline IV & $5(42)$ \\
\hline \multicolumn{2}{|l|}{ Aneurysm location } \\
\hline $\mathrm{ACo} A$ & $5(42)$ \\
\hline MCA & $1(8)$ \\
\hline OphA & $1(8)$ \\
\hline PICA & $1(8)$ \\
\hline PCoA & $4(33)$ \\
\hline \multicolumn{2}{|l|}{ Treatment } \\
\hline Clip & $5(42)$ \\
\hline Coil & $7(58)$ \\
\hline
\end{tabular}

$\mathrm{ACoA}=$ anterior communicating artery; OphA = ophthalmic artery; $\mathrm{PCoA}=$ posterior communicating artery; PICA = posterior inferior cerebellar artery.

* Values are number of patients (\%) unless stated otherwise.

had mild, 6 (50\%) moderate, and 5 (42\%) severe CVS on pre-sildenafil DSA. Angiography occurred on average at posthemorrhage Day 7 (range Days 5-10). Eight (67\%) were found to have a positive angiographic response to sildenafil (3 [60\%] in the low-dose group and 5 [71\%] in the high-dose group [difference in response rate not significant]). No patient was found to have worsening CVS following sildenafil infusion. Examples of angiographic improvement are seen in Figs. 3 and 4.

The largest degree of vessel dilation, across all patients (both low- and high-dose groups), was an average of 0.8 $\mathrm{mm}$ (range $0-2.1 \mathrm{~mm}$ ). This corresponded to an average percentage increase in vessel diameter of 62\% (range $0 \%-200 \%$ ). When considering only patients identified as angiographic responders, the average dilation was $1.1 \mathrm{~mm}$ in the low-dose group and $1.2 \mathrm{~mm}$ in the high-dose group.

\section{Discussion}

The data from this Phase I clinical trial investigating the use of sildenafil for the treatment of angiographic CVS 
TABLE 2. Vital sign data

\begin{tabular}{|c|c|c|c|c|c|c|c|c|}
\hline $\begin{array}{l}\text { Case } \\
\text { No. }\end{array}$ & $\begin{array}{l}\text { Sildenafil } \\
\text { Dose (mg) }\end{array}$ & $\begin{array}{c}\text { Maximum } \\
\text { Drop in MAP } \\
\text { (\% from baseline) }\end{array}$ & $\begin{array}{l}\text { Time to Return } \\
\text { to Baseline } \\
\text { MAP (mins) }\end{array}$ & $\begin{array}{c}\text { Drop in MAP } \\
\text { Post-Nimodipine } \\
\text { (\% from baseline) }\end{array}$ & $\begin{array}{l}\text { Pre-Sildenafil } \\
\text { ICP (mm Hg) }\end{array}$ & $\begin{array}{l}\text { Post-Sildenafil } \\
\text { ICP (mm Hg) }\end{array}$ & $\begin{array}{c}\text { Pre-Sildenafil } \\
\text { Heart } \\
\text { Rate (bpm) }\end{array}$ & $\begin{array}{c}\text { Post-Sildenafil } \\
\text { Heart } \\
\text { Rate (bpm) }\end{array}$ \\
\hline 1 & 10 & 35 & 40 & 12 & 26 & 20 & 93 & 78 \\
\hline 2 & 10 & 16 & 30 & 14 & 13 & 7 & 83 & 75 \\
\hline 3 & 10 & 8 & 0 & 8 & - & - & 71 & 80 \\
\hline 4 & 10 & 16 & 10 & 6 & 5 & 13 & 68 & 74 \\
\hline 5 & 10 & 6 & 0 & 6 & - & - & 84 & 82 \\
\hline 6 & 30 & 21 & 50 & 22 & 9 & 7 & 71 & 79 \\
\hline 7 & 30 & 34 & 15 & 5 & 11 & 8 & 96 & 93 \\
\hline 8 & 30 & 17 & 20 & 9 & 15 & 8 & 83 & 81 \\
\hline 9 & 30 & 12 & 15 & 14 & 12 & 8 & 104 & 104 \\
\hline 10 & 30 & 15 & 25 & 8 & 8 & 4 & 105 & 110 \\
\hline 11 & 30 & 12 & 5 & 23 & 9 & 9 & 65 & 75 \\
\hline 12 & 30 & 11 & 10 & 9 & 27 & 24 & 45 & 45 \\
\hline
\end{tabular}

provide the first evidence that sildenafil in the setting of aneurysmal SAH is both safe and well tolerated. This is the first study to demonstrate in a rigorous fashion that sildenafil has a beneficial effect on CVS in humans.

In evaluating the safety of sildenafil in this patient population, our primary concern was that it would induce unacceptable hypotension. We have seen from other promising trials that hypotension is a potential confounder affecting patient outcomes. ${ }^{48,49,51}$ We have shown that at both a low dose $(10 \mathrm{mg})$ and a high dose $(30 \mathrm{mg})$, the blood pressure profile is acceptable without evidence of a prolonged adverse effect. While there was a decline in MAP by an average of $17 \%$, this was transient with a rapid return to baseline within an average of 18 minutes (Table 2). There was no evidence that this response was dose dependent. When comparing the mild hypotension after sildenafil to that encountered after nimodipine, we found no significant difference between the 2 drugs (Table 2). Furthermore, the hypotension seen after nimodipine developed 1 hour fol- lowing ingestion, whereas with sildenafil all patients had returned to baseline within 1 hour. Other encouraging data suggesting the safety of sildenafil in the SAH patients are the lack of an adverse impact on ICP and/or cardiopulmonary status. Furthermore, previously described issues surrounding its tolerability (flushing, headaches, visual decline, and etc.) were not encountered.

Angiographically, $62 \%$ of patients demonstrated a positive response. There was no significant variance related to dose. Though the degree of vessel dilation was modest in absolute magnitude (average improvement of $0.8 \mathrm{~mm} ; 62 \%$ increase in vessel diameter), when comparing this intravenously dosed medication to reported response rates for intraarterial papaverine and verapamil (response rates of $67 \%-98 \%$; vessel diameter increases of $26 \%-44 \%), 16,43,54$ our observed response to sildenafil was quite promising. It should be noted that the angiographic effects reported here were focal areas of dilation in specific vasospastic vessels (Figs. 3 and 4); the response was not necessarily a global

TABLE 3. Angiographic data

\begin{tabular}{|c|c|c|c|c|c|}
\hline Case No. & Vasospasm Grade & Sildenafil Dose (mg) & Improve Post-Sildenafil & Maximum Dilatation (mm) & Maximum Dilatation (\%) \\
\hline 1 & Severe & 10 & Yes & 1.25 & 100 \\
\hline 2 & Moderate & 10 & Yes & 1.25 & 100 \\
\hline 3 & Moderate & 10 & No & NR & NR \\
\hline 4 & Moderate & 10 & No & NR & NR \\
\hline 5 & Moderate & 10 & Yes & 0.83 & 25 \\
\hline 6 & Moderate & 30 & No & NR & NR \\
\hline 7 & Severe & 30 & Yes & 1.25 & 100 \\
\hline 8 & Moderate & 30 & No & NR & NR \\
\hline 9 & Severe & 30 & Yes & 2.1 & 200 \\
\hline 10 & Severe & 30 & Yes & 1.25 & 100 \\
\hline 11 & Severe & 30 & Yes & 0.6 & 71 \\
\hline 12 & Mild & 30 & Yes & 0.6 & 50 \\
\hline
\end{tabular}

$\mathrm{NR}=$ nonresponder. 

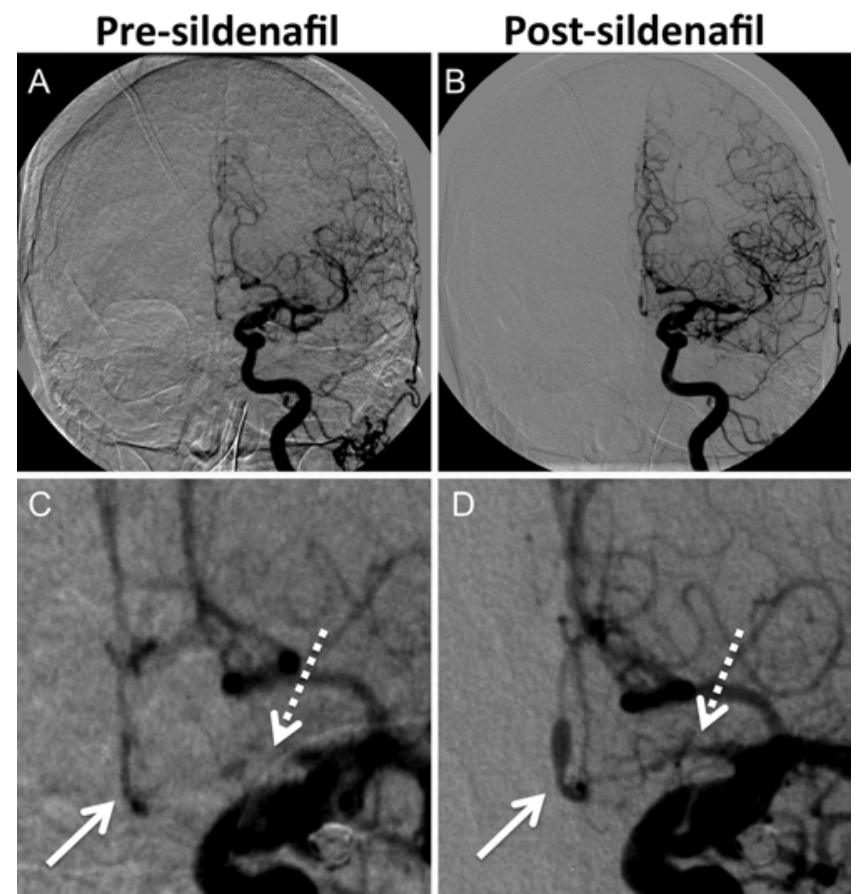

FIG. 3. A: The anteroposterior DSA image of a left carotid artery injection prior to sildenafil. B: The anteroposterior DSA image of the same left carotid artery following sildenafil infusion. C: A zoomed image of the pre-sildenafil angiogram, showing severe CVS of the left $A_{1}$ and $A_{2}$ segments of the anterior cerebral arteries (white arrows). D: Demonstrates areas of dilation in the proximal left $A_{1}$ (dotted arrow) and $A_{2}$ (solid arrow) segments of the anterior cerebral artery post-sildenafil.

improvement in the degree of vasospasm. Therefore, we are not claiming that our results prove that sildenafil "reverses" CVS, but we do believe our findings demonstrate a "proof-of-concept" that sildenafil is acting in positive way on the pathophysiology of cerebral vasospasm.

\section{Sildenafil as Treatment for $\mathrm{DCl}$}

The vasodilatory effect seen with sildenafil has been primarily attributed to its modulation of the eNOS-NOcGMP pathway. ${ }^{14,27}$ It has long been understood that a significant component of the development of SAH-induced CVS has been the dysfunction of the eNOS-NO-cGMP pathway, and numerous interventions designed to upregulate this pathway have been shown to improve CVS in preclinical and, at times, clinical studies. ${ }^{12,34,38,40,59,72,76,77,84}$ The majority of these interventions have targeted the upstream elements of this molecular cascade (eNOS and NO). Results from these upstream therapeutic approaches, however, have been disappointing due to a lack of specific and effective eNOS agonists as well as a myriad of difficulties associated with NO-directed therapies including the short half-life of available NO donors and the substantial systemic side effects such agents often induce..$^{15}$ As a result, many investigators have begun to target the downstream element of the eNOS-NO-cGMP pathway by administering PDE-V inhibitors like sildenafil as a means for inhibiting SAH-induced CVS and DCI.

In animal studies, PDE-V inhibition attenuates or
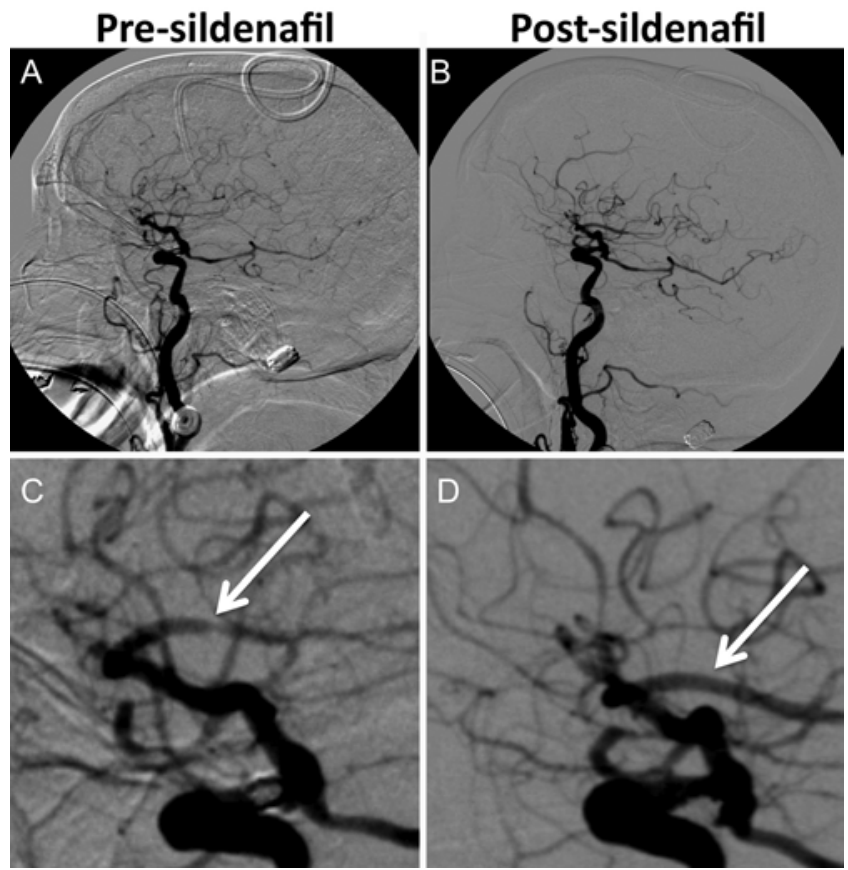

FIG. 4. A: The lateral DSA image of a left carotid artery injection prior to sildenafil. B: Lateral DSA image of the same left carotid artery following sildenafil infusion. C: A zoomed image of the pre-sildenafil angiogram showing a focal area of stenosis in the superior $\mathrm{M}_{2}$ division of the middle cerebral artery (arrow). D: Improvement in the vasospasm is seen in the $M_{2}$ segment of the MCA following sildenafil infusion. The focal area of stenosis has resolved (arrow).

acutely reverses SAH-induced $\mathrm{CVS}, 2,28,31,32,34,42$ reduces $\mathrm{SAH}$-induced neuronal cell death, ${ }^{32}$ and improves postSAH neurological outcome. ${ }^{32}$ PDE-V inhibition has also been shown to augment autoregulatory vasodilatation in humans without $\mathrm{SAH}^{10}$ and, in a rat model of $\mathrm{SAH}$, restore impaired autoregulatory mechanisms. ${ }^{73}$ More recently in SAH patients, sildenafil has been shown to have a positive effect on transcranial Doppler flow velocities in refractory CVS. ${ }^{56}$

The hypothesized mechanism through which sildenafil and other PDE-V inhibitors exert their beneficial vascular effects has been in their ability to increase intracellular cGMP levels in vascular smooth muscle cells, and, as a result, normalize vascular tone. ${ }^{32}$ However, there are other pathways through which PDE-V inhibition may also be acting. Endothelin-1, a potent cerebral vasoconstrictor, has been strongly implicated in early brain injury, CVS, and ultimately DCI following aneurysmal SAH. $3,29,36,37,39,46,48,50-$ $53,75,79,86$ Studies evaluating endothelial function in erectile dysfunction and pulmonary hypertension have demonstrated that sildenafil substantially reduces endothelin-1 levels. ${ }^{44,60,64,65}$ The development of platelet-induced microthrombi within the microvasculature has also been implicated in DCI, ${ }^{20-22,63,70}$ and sildenafil has been shown to limit this prothrombotic cascade..$^{30,45,62,68,83}$ Lastly, when cerebral blood flow to an area decreases to ischemic levels, sildenafil has demonstrated the ability to decrease the size of the infarct and improve outcomes by promoting angiogenesis in hypoxic areas. ${ }^{14,66,87-89}$ Each of these pathways 
represents future areas of study in determining sildenafil's role in treating DCI.

\section{Study Limitations}

The aims of this study were to assess the safety of sildenafil in SAH patients with CVS and to determine whether sildenafil results in a positive angiographic response. With the prescribed doses $(10 \mathrm{mg}$ and $30 \mathrm{mg}$ ), we were able to achieve both goals. However, it is possible that sildenafil was under-dosed. Studies evaluating safety and efficacy in pulmonary hypertension, have determined that oral dosing up to $300 \mathrm{mg}$ /day in divided doses (comparable to $150 \mathrm{mg}$ / day intravenously) can be achieved safely. ${ }^{24,67}$ Our initial concern was that the systemic vasodilatation would result in an unacceptable degree of hypotension and/or an adverse impact on ICP. Since we have now demonstrated that a single infusion is well tolerated, future studies will need to increase the prescribed dosage level in combination with changing the dosing scheme to daily divided doses continuing through the vasospasm window.

Second, the relatively small number of patients included in our study precludes us from making definitive conclusions regarding sildenafil's impact on CVS and neurological outcomes. Assessing neurological outcome was outside the scope of this Phase I trial. Also, as we have previously discussed, our angiographic analysis was a proof-of-concept, being used to demonstrate a positive physiological response in the setting of CVS. Future clinical trials will need to be randomized and adequately powered to make meaningful assessments as to the effects of sildenafil on CVS and patient outcomes.

\section{Conclusions}

The results from this Phase I safety and proof-of-concept trial assessing the use of intravenous sildenafil in patients with angiographic CVS show that sildenafil is safe and well tolerated in the setting of SAH. Furthermore, the angiographic data are the first of its kind to provide evidence that sildenafil has a positive impact on CVS. This information, along with the substantial amount of preclinical data in SAH studies and sildenafil's proven track record in treating other pathophysiologies related to vascular endothelium dysfunction, provides a strong rationale for future clinical investigations into its effectiveness in preventing and treating SAH-related DCI.

\section{Acknowledgments}

Funding was provided by Washington University Institute of Clinical and Translational Sciences grant no. UL1 TR000448 from the National Center for Advancing Translational Sciences of the National Institutes of Health, and the Neurosurgery Research and Education Foundation.

\section{References}

1. Abbott D, Comby P, Charuel C, Graepel P, Hanton G, Leblanc B, et al: Preclinical safety profile of sildenafil. Int J Impot Res 16:498-504, 2004

2. Atalay B, Caner H, Cekinmez M, Ozen O, Celasun B, Altinors N: Systemic administration of phosphodiesterase $\mathrm{V}$ inhibitor, sildenafil citrate, for attenuation of cerebral vasospasm after experimental subarachnoid hemorrhage. Neurosurgery 59:1102-1108, 2006

3. Bellapart J, Jones L, Bandeshe H, Boots R: Plasma endothelin-1 as screening marker for cerebral vasospasm after subarachnoid hemorrhage. Neurocrit Care 20:77-83, 2014

4. Connolly ES Jr, Rabinstein AA, Carhuapoma JR, Derdeyn $\mathrm{CP}$, Dion J, Higashida RT, et al: Guidelines for the management of aneurysmal subarachnoid hemorrhage: a guideline for healthcare professionals from the American Heart Association/American Stroke Association. Stroke 43:1711-1737, 2012

5. Conti CR, Pepine CJ, Sweeney M: Efficacy and safety of sildenafil citrate in the treatment of erectile dysfunction in patients with ischemic heart disease. Am J Cardiol 83 (5A):29C-34C, 1999

6. Cossu G, Messerer M, Oddo M, Daniel RT: To look beyond vasospasm in aneurysmal subarachnoid haemorrhage. Biomed Res Int 2014:628597, 2014

7. Crowley RW, Medel R, Dumont AS, Ilodigwe D, Kassell NF, Mayer SA, et al: Angiographic vasospasm is strongly correlated with cerebral infarction after subarachnoid hemorrhage. Stroke 42:919-923, 2011

8. Dankbaar JW, Rijsdijk M, van der Schaaf IC, Velthuis BK, Wermer MJH, Rinkel GJE: Relationship between vasospasm, cerebral perfusion, and delayed cerebral ischemia after aneurysmal subarachnoid hemorrhage. Neuroradiology 51:813-819, 2009

9. Das A, Xi L, Kukreja RC: Phosphodiesterase-5 inhibitor sildenafil preconditions adult cardiac myocytes against necrosis and apoptosis. Essential role of nitric oxide signaling. J Biol Chem 280:12944-12955, 2005

10. Diomedi M, Sallustio F, Rizzato B, Ferrante F, Leone G, Spera E, et al: Sildenafil increases cerebrovascular reactivity: a transcranial Doppler study. Neurology 65:919-921, 2005

11. Dorsch N: A clinical review of cerebral vasospasm and delayed ischaemia following aneurysm rupture, in Acta Neurochir Suppl 110:5-6, 2011

12. Edwards DH, Byrne JV, Griffith TM: The effect of chronic subarachnoid hemorrhage on basal endothelium-derived relaxing factor activity in intrathecal cerebral arteries. J Neurosurg 76:830-837, 1992

13. Etminan N, Vergouwen MDI, Ilodigwe D, Macdonald RL: Effect of pharmaceutical treatment on vasospasm, delayed cerebral ischemia, and clinical outcome in patients with aneurysmal subarachnoid hemorrhage: a systematic review and meta-analysis. J Cereb Blood Flow Metab 31:1443-1451, 2011

14. Farooq MU, Naravetla B, Moore PW, Majid A, Gupta R, Kassab MY: Role of sildenafil in neurological disorders. Clin Neuropharmacol 31:353-362, 2008

15. Fathi AR, Bakhtian KD, Pluta RM: The role of nitric oxide donors in treating cerebral vasospasm after subarachnoid hemorrhage. Acta Neurochir Suppl 110:93-97, 2011

16. Feng L, Fitzsimmons BF, Young WL, Berman MF, Lin E, Aagaard BD, et al: Intraarterially administered verapamil as adjunct therapy for cerebral vasospasm: safety and 2-year experience. AJNR Am J Neuroradiol 23:1284-1290, 2002

17. Fergusen S, Macdonald RL: Predictors of cerebral infarction in patients with aneurysmal subarachnoid hemorrhage. Neurosurgery 60:658-667, 2007

18. Fox KM, Thadani U, Ma PT, Nash SD, Keating Z, Czorniak $\mathrm{MA}$, et al: Sildenafil citrate does not reduce exercise tolerance in men with erectile dysfunction and chronic stable angina. Eur Heart J 24:2206-2212, 2003

19. Friebe A, Koesling D: Regulation of nitric oxide-sensitive guanylyl cyclase. Circ Res 93:96-105, 2003

20. Friedrich B, Müller F, Feiler S, Schöller K, Plesnila N: Experimental subarachnoid hemorrhage causes early and 
long-lasting microarterial constriction and microthrombosis: an in-vivo microscopy study. J Cereb Blood Flow Metab 32:447-455, 2012

21. Friedrich V, Flores R, Muller A, Sehba FA: Escape of intraluminal platelets into brain parenchyma after subarachnoid hemorrhage. Neuroscience 165:968-975, 2010

22. Friedrich V, Flores R, Muller A, Sehba FA: Luminal platelet aggregates in functional deficits in parenchymal vessels after subarachnoid hemorrhage. Brain Res 1354:179-187, 2010

23. Frontera JA, Claassen J, Schmidt JM, Wartenberg KE, Temes $\mathrm{R}$, Connolly ES Jr, et al: Prediction of symptomatic vasospasm after subarachnoid hemorrhage: the modified fisher scale. Neurosurgery 59:21-27, 2006

24. Galiè N, Ghofrani HA, Torbicki A, Barst RJ, Rubin LJ, Badesch D, et al: Sildenafil citrate therapy for pulmonary arterial hypertension. N Engl J Med 353:2148-2157, 2005

25. García-Cardoso J, Vela R, Mahillo E, Mateos-Cáceres PJ, Modrego J, Macaya C, et al: Increased cyclic guanosine monophosphate production and endothelial nitric oxide synthase level in mononuclear cells from sildenafil citrate-treated patients with erectile dysfunction. Int J Impot Res 22:68-76, 2010

26. Gebska MA, Stevenson BK, Hemnes AR, Bivalacqua TJ, Haile A, Hesketh GG, et al: Phosphodiesterase-5A (PDE5A) is localized to the endothelial caveolae and modulates NOS3 activity. Cardiovasc Res 90:353-363, 2011

27. Ghofrani HA, Osterloh IH, Grimminger F: Sildenafil: from angina to erectile dysfunction to pulmonary hypertension and beyond. Nat Rev Drug Discov 5:689-702, 2006

28. Gokce C, Gulsen S, Yilmaz C, Guven G, Caner H, Altinors $\mathrm{N}$ : The effect of the sildenafil citrate on cerebral vasospasm and apoptosis following experimental subarachnoid hemorrhage in rats. J Neurosurg Sci 54:29-37, 2010

29. Gruber A, Roessler K, Georgopoulos A, Missbichler A, Bonelli R, Richling B: Evaluation of big endothelin-1 concentrations in serum and ventricular cerebrospinal fluid after early surgical compared with nonsurgical management of ruptured intracranial aneurysms. Neurosurg Focus 8(5):e6, 2000

30. Gudmundsdóttir IJ, McRobbie SJ, Robinson SD, Newby DE, Megson IL: Sildenafil potentiates nitric oxide mediated inhibition of human platelet aggregation. Biochem Biophys Res Commun 337:382-385, 2005

31. Gul S, Bahadir B, Hanci V, Bektas S, Can M, Kalayci M, et al: Effect of vardenafil on cerebral vasospasm following experimental subarachnoid hemorrhage in rats. J Clin Neurosci 17:1038-1041, 2010

32. Han BH, Vellimana AK, Zhou ML, Milner E, Zipfel GJ: Phosphodiesterase 5 inhibition attenuates cerebral vasospasm and improves functional recovery after experimental subarachnoid hemorrhage. Neurosurgery 70:178-187, 2012

33. Hop JW, Rinkel GJ, Algra A, van Gijn J: Case-fatality rates and functional outcome after subarachnoid hemorrhage: a systematic review. Stroke 28:660-664, 1997

34. Inoha S, Inamura T, Ikezaki K, Nakamizo A, Amano T, Fukui M: Type V phosphodiesterase expression in cerebral arteries with vasospasm after subarachnoid hemorrhage in a canine model. Neurol Res 24:607-612, 2002

35. Jackson G, Benjamin N, Jackson N, Allen MJ: Effects of sildenafil citrate on human hemodynamics. Am J Cardiol 83 (5A):13C-20C, 1999

36. Juvela S: Plasma endothelin and big endothelin concentrations and serum endothelin-converting enzyme activity following aneurysmal subarachnoid hemorrhage. J Neurosurg 97:1287-1293, 2002

37. Juvela S: Plasma endothelin concentrations after aneurysmal subarachnoid hemorrhage. J Neurosurg 92:390-400, 2000

38. Kasuya H, Weir BKA, Nakane M, Pollock JS, Johns L, Marton LS, et al: Nitric oxide synthase and guanylate cyclase levels in canine basilar artery after subarachnoid hemorrhage. J Neurosurg 82:250-255, 1995

39. Kasuya H, Weir BKA, White DM, Stefansson K: Mechanism of oxyhemoglobin-induced release of endothelin-1 from cultured vascular endothelial cells and smooth-muscle cells. J Neurosurg 79:892-898, 1993

40. Kim P, Schini VB, Sundt TM Jr, Vanhoutte PM: Reduced production of cGMP underlies the loss of endotheliumdependent relaxations in the canine basilar artery after subarachnoid hemorrhage. Circ Res 70:248-256, 1992

41. Kloner RA, Zusman RM: Cardiovascular effects of sildenafil citrate and recommendations for its use. Am J Cardiol 84 (5B): $11 \mathrm{~N}-17 \mathrm{~N}, 1999$

42. Koktekir E, Erdem Y, Akif Bayar M, Gokcek C, Karatay M, Kilic C: A new approach to the treatment of cerebral vasospasm: the angiographic effects of tadalafil on experimental vasospasm. Acta Neurochir (Wien) 152:463-469, 2010

43. Komotar RJ, Zacharia BE, Otten ML, Mocco J, Lavine SD: Controversies in the endovascular management of cerebral vasospasm after intracranial aneurysm rupture and future directions for therapeutic approaches. Neurosurgery 62:897-907, 2008

44. Konstantinopoulos A, Giannitsas K, Athanasopoulos A, Spathas D, Perimenis P: The impact of daily sildenafil on levels of soluble molecular markers of endothelial function in plasma in patients with erectile dysfunction. Expert Opin Pharmacother 10:155-160, 2009

45. Lewis GD, Witzke C, Colon-Hernandez P, Guerrero JL, Bloch KD, Semigran MJ: Sildenafil improves coronary artery patency in a canine model of platelet-mediated cyclic coronary occlusion after thrombolysis. J Am Coll Cardiol 47:1471-1477, 2006

46. Macdonald RL: Clazosentan: an endothelin receptor antagonist for treatment of vasospasm after subarachnoid hemorrhage. Expert Opin Investig Drugs 17:1761-1767, 2008

47. Macdonald RL: Delayed neurological deterioration after subarachnoid haemorrhage. Nat Rev Neurol 10:44-58, 2014

48. Macdonald RL, Higashida RT, Keller E, Mayer SA, Molyneux A, Raabe A, et al: Clazosentan, an endothelin receptor antagonist, in patients with aneurysmal subarachnoid haemorrhage undergoing surgical clipping: a randomised, double-blind, placebo-controlled phase 3 trial (CONSCIOUS-2). Lancet Neurol 10:618-625, 2011

49. Macdonald RL, Higashida RT, Keller E, Mayer SA, Molyneux A, Raabe A, et al: Randomized trial of clazosentan in patients with aneurysmal subarachnoid hemorrhage undergoing endovascular coiling. Stroke 43:1463-1469, 2012

50. Macdonald RL, Higashida RT, Keller E, Mayer SA, Molyneux A, Raabe A, et al: Preventing vasospasm improves outcome after aneurysmal subarachnoid hemorrhage: rationale and design of CONSCIOUS-2 and CONSCIOUS-3 trials. Neurocrit Care 13:416-424, 2010

51. Macdonald RL, Kassell NF, Mayer S, Ruefenacht D, Schmiedek P, Weidauer S, et al: Clazosentan to overcome neurological ischemia and infarction occurring after subarachnoid hemorrhage (CONSCIOUS-1): randomized, double-blind, placebo-controlled phase 2 dose-finding trial. Stroke 39:3015-3021, 2008

52. Macdonald RL, Pluta RM, Zhang JH: Cerebral vasospasm after subarachnoid hemorrhage: the emerging revolution. Nat Clin Pract Neurol 3:256-263, 2007

53. Mascia L, Fedorko L, Stewart DJ, Mohamed F, terBrugge K, Ranieri VM, et al: Temporal relationship between endothelin-1 concentrations and cerebral vasospasm in patients with aneurysmal subarachnoid hemorrhage. Stroke 32:1185-1190, 2001

54. Milburn JM, Moran CJ, Cross DT III, Diringer MN, Pilgram TK, Dacey RG Jr: Increase in diameters of vasospastic intracranial arteries by intraarterial papaverine administration. J Neurosurg 88:38-42, 1998 
55. Mrozek S, Dumurgier J, Citerio G, Mebazaa A, Geeraerts T: Biomarkers and acute brain injuries: interest and limits. Crit Care 18:220, 2014

56. Mukherjee KK, Singh SK, Khosla VK, Mohindra S, Salunke P: Safety and efficacy of sildenafil citrate in reversal of cerebral vasospasm: A feasibility study. Surg Neurol Int 3:3, 2012

57. Ohman J, Servo A, Heiskanen O: Long-term effects of nimodipine on cerebral infarcts and outcome after aneurysmal subarachnoid hemorrhage and surgery. J Neurosurg 74:8-13, 1991

58. Pluta RM: Dysfunction of nitric oxide synthases as a cause and therapeutic target in delayed cerebral vasospasm after SAH. Acta Neurochir Suppl 104:139-147, 2008

59. Pluta RM, Oldfield EH, Boock RJ: Reversal and prevention of cerebral vasospasm by intracarotid infusions of nitric oxide donors in a primate model of subarachnoid hemorrhage. $\mathbf{J}$ Neurosurg 87:746-751, 1997

60. Proietti M, Aversa A, Letizia C, Rossi C, Menghi G, Bruzziches $\mathrm{R}$, et al: Erectile dysfunction in systemic sclerosis: effects of longterm inhibition of phosphodiesterase type- 5 on erectile function and plasma endothelin-1 levels. J Rheumatol 34:1712-1717, 2007

61. Rabinstein AA, Friedman JA, Weigand SD, McClelland RL, Fulgham JR, Manno EM, et al: Predictors of cerebral infarction in aneurysmal subarachnoid hemorrhage. Stroke 35:1862-1866, 2004

62. Rehse K, Scheffler H, Reitner N: Interaction of Viagra with the NO donors molsidomine and RE 2047 with regard to antithrombotic and blood pressure lowering activities. Arch Pharm (Weinheim) 332:182-184, 1999

63. Romano JG, Rabinstein AA, Arheart KL, Nathan S, CampoBustillo I, Koch S, et al: Microemboli in aneurysmal subarachnoid hemorrhage. J Neuroimaging 18:396-401, 2008

64. Rosano GM, Aversa A, Vitale C, Fabbri A, Fini M, Spera G: Chronic treatment with tadalafil improves endothelial function in men with increased cardiovascular risk. Eur Urol 47:214-222, 2005

65. Rossi R, Nuzzo A, Lattanzi A, Coppi F, Modena MG: Sildenafil improves endothelial function in patients with pulmonary hypertension. Pulm Pharmacol Ther 21:172177,2008

66. Sahara M, Sata M, Morita T, Nakajima T, Hirata Y, Nagai R: A phosphodiesterase-5 inhibitor vardenafil enhances angiogenesis through a protein kinase G-dependent hypoxiainducible factor-1/vascular endothelial growth factor pathway. Arterioscler Thromb Vasc Biol 30:1315-1324, 2010

67. Sastry BK, Narasimhan C, Reddy NK, Raju BS: Clinical efficacy of sildenafil in primary pulmonary hypertension: a randomized, placebo-controlled, double-blind, crossover study. J Am Coll Cardiol 43:1149-1153, 2004

68. Schmidt U, Han RO, DiSalvo TG, Guerrero JL, Gold HK, Zapol WM, et al: Cessation of platelet-mediated cyclic canine coronary occlusion after thrombolysis by combining nitric oxide inhalation with phosphodiesterase-5 inhibition. J Am Coll Cardiol 37:1981-1988, 2001

69. Sehba FA, Friedrich V Jr, Makonnen G, Bederson JB: Acute cerebral vascular injury after subarachnoid hemorrhage and its prevention by administration of a nitric oxide donor. $\mathbf{J}$ Neurosurg 106:321-329, 2007

70. Sehba FA, Mostafa G, Friedrich V Jr, Bederson JB: Acute microvascular platelet aggregation after subarachnoid hemorrhage. J Neurosurg 102:1094-1100, 2005

71. Sobey CG: Cerebrovascular dysfunction after subarachnoid haemorrhage: novel mechanisms and directions for therapy. Clin Exp Pharmacol Physiol 28:926-929, 2001

72. Sobey CG, Faraci FM: Subarachnoid haemorrhage: what happens to the cerebral arteries? Clin Exp Pharmacol Physiol 25:867-876, 1998
73. Sobey CG, Quan L: Impaired cerebral vasodilator responses to NO and PDE V inhibition after subarachnoid hemorrhage. Am J Physiol 277:H1718-H1724, 1999

74. Suarez JI, Tarr RW, Selman WR: Aneurysmal subarachnoid hemorrhage. N Engl J Med 354:387-396, 2006

75. Thampatty BP, Sherwood PR, Gallek MJ, Crago EA, Ren D, Hricik AJ, et al: Role of endothelin-1 in human aneurysmal subarachnoid hemorrhage: associations with vasospasm and delayed cerebral ischemia. Neurocrit Care 15:19-27, 2011

76. Thomas JE, Rosenwasser RH: Reversal of severe cerebral vasospasm in three patients after aneurysmal subarachnoid hemorrhage: initial observations regarding the use of intraventricular sodium nitroprusside in humans. Neurosurgery 44:48-58, 1999

77. Vellimana AK, Milner E, Azad TD, Harries MD, Zhou ML, Gidday JM, et al: Endothelial nitric oxide synthase mediates endogenous protection against subarachnoid hemorrhageinduced cerebral vasospasm. Stroke 42:776-782, 2011

78. Vergouwen MD, Vermeulen M, van Gijn J, Rinkel GJ, Wijdicks EF, Muizelaar JP, et al: Definition of delayed cerebral ischemia after aneurysmal subarachnoid hemorrhage as an outcome event in clinical trials and observational studies: proposal of a multidisciplinary research group. Stroke 41:2391-2395, 2010

79. Vergouwen MDI, Algra A, Rinkel GJE: Endothelin receptor antagonists for aneurysmal subarachnoid hemorrhage: a systematic review and meta-analysis update. Stroke 43:26712676, 2012

80. Wallis RM, Corbin JD, Francis SH, Ellis P: Tissue distribution of phosphodiesterase families and the effects of sildenafil on tissue cyclic nucleotides, platelet function, and the contractile responses of trabeculae carneae and aortic rings in vitro. Am J Cardiol 83 (5A):3C-12C, 1999

81. Webb DJ, Freestone S, Allen MJ, Muirhead GJ: Sildenafil citrate and blood-pressure-lowering drugs: results of drug interaction studies with an organic nitrate and a calcium antagonist. Am J Cardiol 83 (5A):21C-28C, 1999

82. Weyer GW, Nolan CP, Macdonald RL: Evidence-based cerebral vasospasm management. Neurosurg Focus 21(3):E8, 2006

83. Wilson LS, Elbatarny HS, Crawley SW, Bennett BM, Maurice DH: Compartmentation and compartment-specific regulation of PDE5 by protein kinase $\mathrm{G}$ allows selective cGMP-mediated regulation of platelet functions. Proc Natl Acad Sci U S A 105:13650-13655, 2008

84. Wolf EW, Banerjee A, Soble-Smith J, Dohan FC Jr, White RP, Robertson JT: Reversal of cerebral vasospasm using an intrathecally administered nitric oxide donor. J Neurosurg 89:279-288, 1998

85. Yatsushige H, Calvert JW, Cahill J, Zhang JH: Limited role of inducible nitric oxide synthase in blood-brain barrier function after experimental subarachnoid hemorrhage. J Neurotrauma 23:1874-1882, 2006

86. Yeung PK, Shen J, Chung SS, Chung SK: Targeted overexpression of endothelin-1 in astrocytes leads to more severe brain damage and vasospasm after subarachnoid hemorrhage. BMC Neurosci 14:131, 2013

87. Zhang L, Zhang RL, Wang Y, Zhang C, Zhang ZG, Meng $\mathrm{H}$, et al: Functional recovery in aged and young rats after embolic stroke: treatment with a phosphodiesterase type 5 inhibitor. Stroke 36:847-852, 2005

88. Zhang L, Zhang Z, Zhang RL, Cui Y, LaPointe MC, Silver B, et al: Tadalafil, a long-acting type 5 phosphodiesterase isoenzyme inhibitor, improves neurological functional recovery in a rat model of embolic stroke. Brain Res 1118:192-198, 2006

89. Zhang R, Wang L, Zhang L, Chen J, Zhu Z, Zhang Z, et al: Nitric oxide enhances angiogenesis via the synthesis of vas- 
cular endothelial growth factor and cGMP after stroke in the rat. Circ Res 92:308-313, 2003

90. Zusman RM, Morales A, Glasser DB, Osterloh IH: Overall cardiovascular profile of sildenafil citrate. Am J Cardiol 83 (5A):35C-44C, 1999

91. Zusman RM, Prisant LM, Brown MJ: Effect of sildenafil citrate on blood pressure and heart rate in men with erectile dysfunction taking concomitant antihypertensive medication. J Hypertens 18:1865-1869, 2000

\section{Disclosure}

Dr. Derdeyn reports that he has ownership in Pulse Therapeutics and is a consultant for MicroVention and Penumbra.

\section{Author Contributions}

Conception and design: Washington, Derdeyn, Han, Vellimana, Zipfel. Acquisition of data: Washington, Arias, Cross, Moran.
Analysis and interpretation of data: Washington, Derdeyn, Dhar. Drafting the article: Washington. Critically revising the article: all authors. Reviewed submitted version of manuscript: all authors. Approved the final version of the manuscript on behalf of all authors: Washington. Statistical analysis: Washington. Study supervision: Washington, Zipfel.

\section{Supplemental Information}

Previous Presentation

This paper was presented in abstract form at the American Heart Association/American Stroke Association 2014 International Stroke Conference and Nursing Symposium in San Diego, CA.

\section{Correspondence}

Chad Washington, Department of Neurological Surgery,

University of Mississippi Medical Center, 2500 North State St., Jackson, MS 39216. email: cwashington4@umc.edu. 